\title{
Discarded fish in European waters: general patterns and contrasts
}

\author{
Sebastian S. Uhlmann ${ }^{1,{ }^{*}}$, Aloysius T. M. van Helmond ${ }^{1}$, Elísabet Kemp Stefánsdóttir ${ }^{2}$, \\ Sigríður Sigurðardóttir ${ }^{2}$, John Haralabous ${ }^{3}$, Jose Maria Bellido ${ }^{4}$, A. Carbonell ${ }^{4}$, Tom Catchpole ${ }^{5}$ \\ Dimitrios Damalas ${ }^{6}$, Laurence Fauconnet ${ }^{7}$, Jordan Feekings ${ }^{8}$, Teresa Garcia ${ }^{4}$, Niels Madsen ${ }^{8}$, \\ Sandra Mallold ${ }^{4}$, Sveinn Margeirsson ${ }^{2}$, Andreas Palialexis ${ }^{3}$, Lisa Readdy ${ }^{5}$, Julio Valeiras ${ }^{4}$, \\ Vassiliki Vassilopoulou ${ }^{3}$ and Marie-Joëlle Rochet ${ }^{7}$
}

\footnotetext{
1 IMARES Wageningen UR, Haringkade 1, 1976 CP IJmuiden, The Netherlands

${ }_{3}^{2}$ Matís, Icelandic Food and Biotech R\&D, Vínlandsleið 12, 113 Reykjavík, Iceland

${ }^{3}$ Institute of Marine Biological Resources, Hellenic Centre for Marine Research, Agios Kosmas, Hellinikon, 16610 Athens, Greece

4 Instituto Español de Oceanografía, Centro Oceanográfico de Murcia, c/Varadero, 1, 30740 San Pedro del Pinatar, Murcia, Spain

${ }^{5}$ Cefas, Pakefield Road, Lowestoft, Suffolk NR33 OHT, UK

${ }^{6}$ European Commission, Joint Research Centre, Institute for the Protection and Security of the Citizen, Maritime Affairs Unit, via E. Fermi 2749 , I-21027 Ispra (VA), Italy

${ }^{7}$ IFREMER, Rue de l'lle d'Yeu, 44311 Nantes, France

${ }^{8}$ Technical University of Denmark, National Institute of Aquatic Resources, North Sea Science Park, PO Box 101, DK-9850 Hirtshals, Denmark
}

\author{
*: Corresponding author : Sebastian S. Uhlmann, tel: +31317 480133 ; fax: +31317487326 ; email address : \\ sebastian.uhlmann@wur.nl
}

\begin{abstract}
:
To reduce the practice of discarding commercially fished organisms, several measures such as a discard ban and extra allowances on top of landings quotas ("catch quota") have been proposed by the European Commission. However, for their development and successful implementation, an understanding of discard patterns on a European scale is needed. In this study, we present an international synthesis of discard data collected on board commercial, towed-gear equipped vessels operating under six different national flags spanning from the Baltic to the Mediterranean Seas mainly between 2003 and 2008. We considered discarded species of commercial value such as Atlantic cod (Gadus morhua), haddock (Melanogrammus aeglefinus), European hake (Merluccius merluccius), and European plaice (Pleuronectes platessa). Comparisons of discard per unit effort rates expressed as numbers per hour of fishing revealed that in the Mediterranean Sea minimum size-regulated species such as hake are generally discarded in much lower numbers than elsewhere. For most species examined, variability in discard rates across regions was greater than across fisheries, suggesting that a region-by-region approach to discard reduction would be more relevant. The high uncertainty in discard rate estimates suggests that current sampling regimes should be either expanded or complemented by other data sources, if they are to be used for setting catch quotas.
\end{abstract}

Keywords: Bycatch ; Common Fisheries Policy reform ; Data Collection Framework ; discard reduction ; Europe ; monitoring 
52 Discarding unwanted catch at sea in response to regulatory and/or market forces during commercial fishing is generally considered to be a waste of natural resources. It evades the

54 eyes and often goes unrecorded. But, knowing how much is lost is important, for at least three reasons: firstly, discards might make up a large part of the total catch, possibly exceeding the amount of landings; secondly, stock viability and productivity may be compromised if large, and unregistered numbers of organisms are removed periodically on

58 top of the registered landings (Crowder and Murawski, 1998; Punt et al., 2006); thirdly, quantification of the magnitude of discarding is the first step in a framework to resolve it

60 (Kennelly and Broadhurst, 2002).

62 In Europe, estimating the amount of discards is legislated via the Data Collection Framework ('DCF'; EEC, 2000). As part of nationally-adopted onboard observer programmes, trained

64 personnel collect the biomass, length, age and species compositions of discards from their most important commercial fisheries (EEC, 2009), with the main aim to feed these data into

66 stock assessments. This is done via at-sea sampling (ICES, 2011), and all the data are stored and administered by the respective national authorities. Although various analyses of these

68 data have been done, many studies were restricted to regional fisheries (e.g. Stratoudakis et al., 1999; Viana et al., 2011; Feekings et al., 2012; Madsen et al.,2013). However,

70 synthesizing discard data from as many different fisheries, regions and countries as possible is required to facilitate European-wide management approaches. So far, such a synthesis was

72 hampered by i) the diversity of procedures in collecting and processing data, ii) the disparate intensities of sampling compared to total fishing effort across countries, iii) the lack of a

74 common data exchange format and storage facility, and iv) national regulations which precluded sharing of detailed commercial catch data (STECF, 2006, 2008; Hinz et al., 2013). 
Considering that a reduction of discards is set to be a cornerstone of the European Common

78 Fisheries Policy (CFP) reform (EEC, 2011), a comprehensive pan-European synthesis of discard data across species, fishing regions and fleets is important. This may aid the

80 decision-making process by providing input to questions such as on what level discardreduction initiatives need to be implemented: species, fisheries, or region-based (i.e. fishing

82 ground). An important component of the CFP-reform proposal is a landing obligation, or discard ban, prohibiting the at-sea disposal of some commercially-valuable species from 2014

84 onwards (Article 15; EEC, 2011; EEC, 2012a). Alternatively, catch quota could substitute the current landings quota (EEC, 2011). In either case, the complete catch would need to be

86 accounted for. Shifting from a landings to a catch quota management system would require that catch quotas are set based on reliable estimates of discarded amounts and/or proportions.

88 However, discard rates of a given species are likely to fluctuate within a fishery (e.g. Feekings et al., 2012; Poos et al.,2013) and/or across different fisheries, seasons, years and

90 regions (Stratoudakis et al., 1999; Borges et al., 2005; Borges et al., 2006). The starting point for designing mitigation measures and management plans to reduce discards is to describe 92 and characterise these patterns.

94 In this study, onboard observer data from discard-intensive fisheries using towed gears from Denmark, England, France, Greece, The Netherlands, and Spain were compiled. These data 96 were used to describe species-specific discard patterns among and between fisheries and regions. Owing to logistical and financial constraints, only a fraction of operations carried

98 out by a fleet can be monitored, which will render extrapolations across the entire population of operations uncertain (Depestele et al., 2011). Extrapolations require the use of raising or

100 auxiliary variables such as landings or fishing effort. Following ICES (2011) this could be done "according to sampling theory [where] the standard raising procedure within a given 
stratum (e.g. quarter and area) should be: i) samples are raised to haul level based on sampled proportion; ii) sampled hauls are raised to trip level based on the proportion of hauls sampled; and iii) sampled trips are raised to métier level based on the proportion of trips sampled". But, the availability and quality of raising variables is not uniform and varies 106 across countries (ICES, 2007), so that no single raising procedure can be recommended at the European level (ICES, 2011). For example, the total number of trips within a stratum may

108 not be known, or may be either over- or underestimated due to the switching of gears throughout a trip or depending on post-stratification methods (ICES, 2010). To circumvent 110 these issues, discard estimates at the level of sampled trips are presented here.

112 To allow for an integration and comparison of discard data from various fisheries and national sampling programmes, an index has to be defined that takes into account the unit of fishing

114 effort (i.e. DPUE, Discards per Unit of Effort; Rochet and Trenkel, 2005). Fishing effort measured as the hours spent actually fishing is a commonly-used effort descriptor among EU

116 member states for towed gears. A DPUE index of abundance, hereafter called 'discard rate', can be a useful tool for policy makers to identify discard-intensive fisheries and improve

118 discard management by developing mitigation strategies. Another useful measure, is the ratio between discards and catch (discards and landings). Thus, in this study, we combined discard 120 data from six different countries and several different regions (spanning from the Baltic to the Mediterranean Seas) to compare discard rates of commercially-valuable species such as

122 Atlantic cod (Gadus morhua); haddock (Melanogrammus aeglefinus); European hake (Merluccius merluccius); and European plaice (Pleuronectes platessa). The aim was to contrast discard rates and ratios between fisheries or regions. We compared the coefficients of variation of discard rates and ratios across fisheries for a given region and across regions

126 for a given fishery. If discard patterns were found to be more homogeneous across regions than fisheries, a fisheries-by-fisheries approach to discard reduction might be more relevant. 
130 2. Material and methods

$132 \quad 2.1$ Dataset

A dataset was built from pre-processed and aggregated trip-level information that was

134 provided by each partner detailing the mean ( \pm standard deviation) number of discarded/landed species per hour from sampled trips per metier, fishing region, sub-region;

136 together with the corresponding number of sampled trips from towed gears. Thereby, fishing activity was linked to the European level 5 métier definition, requiring data at the level of

138 fishing ground (hereafter 'region'), gear type, and target species assemblage (e.g. demersal fish - hereafter 'fish', small pelagic fish, cephalopods and fish, crustaceans, crustaceans and

140 fish; FAO, 1980; EEC, 2008; ICES, 2009). Hereafter the term 'fishery' is used to designate a gear type and target species assemblage combination. All biological data such as the numbers

142 and weights (where available) of discarded and landed species were summarized by region, sub-area per region (i.e. ICES Divisions or FAO areas of the Mediterranean Sea), métier and

144 vessel flag country (hereafter country) together with technical information (average trip duration, fleet size and fishing effort). ICES Division 'IIIa' was subdivided into Skagerrak

146 and Kattegat to reflect the stock classifications used by ICES. A summary of a detailed comparison of each of the national discard sampling programmes is provided in Table 1.

Biological data were collected on a haul-by-haul basis and, for the majority of samples,

150 consisted of landings and discard observations of commercially-valuable species (including invertebrates such as crustaceans, molluscs and cephalopods). Numbers discarded, numbers

152 landed (when these were registered), and lengths $(\mathrm{cm})$ were recorded. For the purpose of our study, numbers rather than weights were used, because species weights of catch and discards 
154 were not recorded in all national sampling programmes owing to the challenge of obtaining accurate weight measurements at sea. Although length-weight relationships may have

156 allowed for transformations of available numbers-at-length into weights, this approach was not chosen, because it would have implied the mixing of measurements (available from $n=5$

158 partners; Table 1) with estimated weights (theoretically available from $n=2$ partners, Table 1) when combining data from different countries. All numbers were raised to the haul level (if a

160 sub-sample was measured; based on the proportion between the total and sampled fraction) and subsequently to the trip level (based on either the proportion of sampled fishing

162 operations or fishing time; see Table 1 and ICES, 2011 for details)). These raised numbers of landings and discards per species per sampled trip were standardized by sampled fishing time

164 (i.e. tow duration, in hours) to derive a discard rate (i.e. DPUE), as the numbers landed or discarded per hour per sampled trip. The ratio between discards and catch (discards +

166 landings) rates was used as the discard ratio. From all sampled trips, an average and a standard deviation was then calculated for discard rates and ratios as follows.

2.2 Estimation of discard rates and ratios and their variability

170 To compare species-specific discard rates and ratios (at the level of sampled trips) across regions and fisheries, means and standard deviations across countries and sub-areas within 172 regions were combined. The most appropriate auxiliary variables, such as total fishing effort, were not available in comparable units at the required level of aggregation and desired quality

174 from all countries. Therefore, discard rates were weighted by national sampling effort (i.e. number of observed trips) under the assumption that sampling effort was proportional to a

176 fleet's activity. Thereby, mean numbers of discarded or landed species per hour and trip were combined for a given fishery and region as: 


$$
M=\sum_{i \in I, k \in K} \frac{n_{i, k} m_{i, k}}{N}
$$

180 Where $M$ is the mean number of a discarded or landed species per given fishery and region and $N$ is the total number of sampled trips per given fishery and region. $I$ is the set of all sub-

182 areas within the region and $K$ is the set of all countries. $n_{i, k}$ is the number of sampled trips in sub-area $i$, by country $k$, for the specified métier; and $m_{i, k}$ is the mean number of a discarded 184 or landed species in sub-area $i$, by country $k$, for the specified fishery.

186 From the standard deviation that was associated with each mean number of a discarded or landed species per hour, the variance $V$ was calculated per species, fishery and region as

188 follows, whereby $v_{i, k}$ is the variance for sub-area $i$, by country $k$, for the specified fishery.

$$
V=\sum_{i \in I, k \in K} \frac{v_{i, k}\left(n_{i, k}-1\right)+\left(m_{i, k}-M\right)^{2} n_{i, k}}{N-1}
$$

In $n=97$ cases, standard deviations ( $S D$, square root of the variance) of discard rates were

192 larger than the mean $(M)$. Available length-frequency distributions (Helmond and Uhlmann, 2011) were graphically examined and found to be positively skewed, which implies that a

194 log-normal distribution would describe the data more appropriately than a normal distribution (Limpert et al., 2001). Accordingly, geometric means (GM) and the multiplicative standard deviation (GSD) were calculated from the combined means $(M)$ and standard deviations following Limpert et al. (2001): 


$$
\begin{aligned}
& G M=\frac{M}{\sqrt{1+\left(\frac{S D}{M}\right)^{2}}} \\
& G S D=\exp \left(\sqrt{\log \left(1+\left(\frac{S D}{M}\right)^{2}\right)}\right)
\end{aligned}
$$

Differences of discard and landings rates (i.e. per unit effort) between fisheries and/or regions 202 are illustrated in bar plots with inferential error bars (Cumming et al., 2007) calculated as:

$$
G S E=G S D^{\frac{1}{\sqrt{N}}}
$$

The inferential error bars show a confidence interval (GM/GSE; GM*GSE) for the median of 206 discarded or landed numbers. 'Discard' or landing rate' hereafter refers to the geometric mean of discarded or landed numbers per hour. Statistical significance at $p<0.05$ was inferred when the gap between error bars was of the same size as the error bar itself with $>10$ sampled trips. For fewer trips a greater gap is needed for a similar significant difference.

As a measure of the variability of discard rates and ratios across fisheries or regions, we computed the coefficient of variation for discards rates and ratios by fisheries and region. To calculate the respective CVs, the average and the standard deviation of discard rates and

214 ratios for a given fishery (across regions) or for a given region (across fisheries) were taken. All calculations were done using the statistical software R (R Development Core Team, 216 2005), with the aid of the 'combinevar' function from the package 'fishmethods' (Nelson, 2012). 


\subsection{Comparison of discard rates and ratios}

220 The comparisons of discard rates and ratios were done specifically for towed-gear fisheries that operated under different national flags. These included otter- (OTB) and beam-trawlers

222 (TBB) targeting crustaceans (CRU) or demersal fish ('fish', DEF; Table 2). Pelagic fisheries which require specific sampling procedures were not considered in this study. To make

224 meaningful i) inter-region (across fishing regions) and ii) inter-fishery (across fisheries) comparisons of species-specific discard rates in the following section, we selected non-

226 pelagic, minimum-landing-size (MLS)-regulated species which were listed in the CFP-reform proposal, and were commonly discarded from the above-mentioned fisheries in a number of

228 different regions, namely: $\operatorname{cod}(\mathrm{MLS}=35 \mathrm{~cm}$ in all regions except Skagerrak/Kattegat, where MLS was decreased to $30 \mathrm{~cm}$ in 2008 and in the Baltic Sea where it was increased to $38 \mathrm{~cm}$ 230 in 2003); haddock (30 cm in all regions apart from Skagerrak/ Kattegat, where it is $27 \mathrm{~cm}$ ); hake $(27 \mathrm{~cm}$ in all regions apart from Skagerrak/Kattegat, $30 \mathrm{~cm}$; and Mediterranean Sea, 20

$232 \mathrm{~cm})$; and plaice $(27 \mathrm{~cm})$. Acknowledging the different species composition of discards in the Mediterranean Sea, for this region the following list was nominated in accordance with the

234 above criteria: bogue (Boops boops; $10 \mathrm{~cm}$ according to national legislation in Greece); red mullet (Mullet barbatus barbatus; $11 \mathrm{~cm}$ ); and deep-water rose shrimp (Parapenaeus

236 longirostris, $2 \mathrm{~cm}$ carapace length).

240 3. Results

242 3.1 Dataset

National discard sampling programmes are not standardized at the European level and exhibit 244 differences in the way vessels are selected for observation, the level of detail that is recorded 
during biological sampling (e.g. species numbers, weights, age, and maturity) and what units

246 of ratio estimators are used to scale up measured numbers (Table 1). Notwithstanding the above, sampling effort and landings and discard rates were compiled for 15 towed-gear

248 fisheries and 11 major European fishing regions (22 ICES Divisions, and five Mediterranean geographic sub-areas (GSA); see Helmond and Uhlmann, 2011 for details). Among these

250 classified fisheries, there were differences in fleet size, fishing effort, and sampling effort between countries (Table 2). Apart from one Greek fishery, generally $<1 \%$ of the number of 252 days spent at sea were observed in any fishery (Table 2).

2543.2 Comparison of discard rates and ratios

Discard rates varied from $<5$ up to $>300$ individuals per hour based on observations between

2564 and 776 sampled trips (Figure 1). Observations from $<4$ trips were not included to avoid using non-representative values which in turn will increase the overall variance. The

258 variability in sampling effort is reflected in the precision of the estimates (Figure 1). With $<10$ observations the uncertainty is large, and even with many samples some discard rates are

260 difficult to estimate precisely owing to the large variability in discarding patterns (e.g. plaice discards by beam trawlers in the North Sea and Eastern Channel have a low precision, even 262 though 100 trips were observed; Figure 1d).

264 Discard rates of cod and haddock (Figure 1a,b) were generally lower than those of hake and plaice (Figure 1c,d). Some of the Mediterranean species such as red mullet and deep-water 266 rose shrimp exhibited the lowest rates (Figure 1e,f). In general, there were distinct patterns when comparing species-specific discard rates across fisheries and regions (Figure 1). For 268 example, discard rates of Atlantic cod were found to be homogenous across fisheries, but were higher in the Skagerrak than in other areas (Table 3; Figure 1a). For haddock, 270 differences of discard rates between regions were larger than between fisheries (Table 3; 
Figure $1 b)$. Hake discard rates were relatively low and similar between different fisheries and

272 regions, except for bottom-otter trawlers targeting fish in the Celtic Sea or crustaceans in the Bay of Biscay (Table 3; Figure 1c). For plaice the differences of discard rates between

274 fisheries, seemed to be of the same order of magnitude than between regions (Table 3; Figure 1d). Notably, discard rates of plaice differed greatly between beam and otter trawls in the

276 North Sea, but were much more homogenous across fisheries in the Irish Sea (Table 3; Figure 1d). In general, otter trawlers targeting crustaceans were observed to discard the majority of 278 the cod, hake, and plaice compared to those targeting fish (Figure 1a-d).

280 Both discard rates and ratios were lower in the Mediterranean Sea than in other regions (Tables 3 and 4; Figure 1e-g). In the Mediterranean Sea, landings rates largely exceeded 282 those of discard rates (Figure 1c, e-f), except for bogue (Figure 1g). Discard ratios of hake were more homogenous than discard rates (Tables 3 and 4). The discard ratios of hake varied more in the Mediterranean Sea than in the Celtic Sea, where hake discards exceeded landings, even though it is a target species by the fleet operating there (Table 4; Figure 1c).

290 Our study highlights the variability of species-specific discard rates at a European scale. A stark contrast was observed between rates in the Mediterranean Sea and the other fishing

292 regions. Further, we found that discard rates were more homogeneous across fisheries than regions, suggesting that discard management measures may be devised at a regional level; for

294 example, by removing quota and catch composition rules (e.g. EEC, 2012b) and incentivising the use of more selective gears. In any case, differences in discard rates between species will 296 also require species-specific approaches to discard reduction such as improvements to gear 
selectivity parameters.

The low level of discarding of MLS-regulated species among Mediterranean otter-trawl

300 fisheries may be a consequence of smaller MLS (e.g. hake), a lack of MLS-compliance and the absence of over-quota discards in a quota-independent management system of Greek

302 demersal trawl fisheries (Catchpole et al., 2013; Damalas and Vassilopoulou, 2013).

Although undersized hake for example are being caught by demersal otter trawlers, the

304 proportion (in weight) of discarded individuals is small (Damalas and Vassilopoulou, 2013).

The fast-growing, small-sized, and highly diverse fish fauna (Stergiou et al., 1997) together

306 with the existence of local markets for small fish and the low probability of prosecution for retaining undersized fish (Damalas and Vassilopoulou, 2013) may be further reasons why a

308 tendency to retain most of the catch exists in this area.

310 Apart from removing quotas and catch composition rules, incentives to increase the use of more selective gears may be another option to reduce discards. One of the more selective

312 gears and fishing methods in our study, where the majority of the target catch was landed, were Danish seines catching cod in the Baltic Sea and plaice in the North Sea (Figure 1b,d).

314 Scottish seines seem equally selective for other target species such as megrim (Lepidorhombus whiffiagonis; Borges et al., 2006). Some gears and methods have become

316 more selective in recent years (beyond the period investigated here) in some areas (e.g. Kattegat and Skagerrak); and their uptake throughout the fishing community was partly

318 promoted by incentives such as an increased quota share, access rights and more fishing days (Madsen and Valentinsson, 2010).

A shortcoming of the current DCF, which complicated the inter-national synthesis of discard 322 data, was the difficulty to agree upon common métier definitions. For example, target species 
assemblage of a level-5-métier could be defined either before the commencement of a trip or

324 after a trip's completion (i.e. by determining its landings compositions). If we had followed the latter rule, it would have resulted in such a large number of métiers, at least among some

326 countries, that it would have rendered an analysis of combined data meaningless. Alternative sampling units other than métiers may be considered for the selection of a sampling frame as

328 part of at-sea monitoring programmes, for example vessels (ICES, 2012). This will also facilitate the standardization of discard sampling approaches (ICES, 2011). Another

330 shortcoming, which hampered our analysis, was the inability to combine both raw data of fishing effort and catch statistics, partly due to the requirements of a data harmonization

332 software for species weights which were not routinely collected in all programmes (Anonymous, 2009; ICES, 2010, 2011) and partly due to confidentiality concerns of releasing 334 detailed, non-aggregated data to a third party (ICES, 2009); the latter is an issue which has hampered also other scientific analyses (Hinz et al., 2013). The lack of recording a species'

336 sub-sampled and total weight in some sampling programmes precluded the use of the COST software (Anonymous, 2009; ICES, 2010).

Data incompatibility and confidentiality were also the reasons, why we ended up contrasting 340 aggregated data at the sampled trip as opposed to the fleet level. However, some inferences from patterns at the trip to the fleet level are possible. For example, the greater variability in

342 discard rates between regions than fisheries may be a consequence of the region-specific quota and landings regulations, if acting as the main drivers of discarding (Catchpole et al.,

344 2013). For example, the main reason for discarding cod by Danish otter trawlers in the Baltic Sea were catches below MLS, whereas in the North Sea and Eastern Channel cod discards 346 were also driven by lack of sufficient quotas (Catchpole et al., 2013). Regional differences in MLS regulations may also be associated with higher discard rates of hake from bottom-otter 348 trawlers in the Celtic Sea (MLS=27 cm), compared with lower rates by the same fishery in 
the Mediterranean Sea (MLS=20 cm; Figure 1).

Nevertheless, the interpretation of differences between discard rates based on the available

352 dataset is difficult for two reasons: firstly, not all species are caught and discarded in significant amounts in all regions, thus for each region we did not necessarily have data on

354 the same species from all countries. Secondly, an additional problem is that the specific reason as to why a species is discarded can often be difficult to disentangle; especially if

356 similar drivers such as quota and MLS regulations exists in different regions or target species vary throughout seasons and fisheries. For example, we have almost exclusively considered

358 CFP-reform-listed fish as opposed to invertebrate crustacean species (other than deep-water rose shrimp) in our analysis. Thereby, we essentially mix comparisons of discard rates of

360 non-target with those of target species. For bottom otter trawlers targeting crustaceans, discarded fish typically exceeded their landings rates during those sampled trips, whereas for

362 those targeting fish the opposite patterns was eminent (Figure 1 a-d) Furthermore, the exact reasons why some fish with an associated landings quota were discarded above MLS can only

364 be inferred (Catchpole et al., 2013); unless fishers (or observers, for example in the US Northeast Fisheries observer programme; Wigley et al., 2012) note why they chose to discard 366 some fish over others (e.g. lack of quota, low market prize, or poor quality). Such reasons together with a plethora of likely other biological, technical, environmental and socio-

368 economic factors will contribute to fluctuating discard rates between species (Borges et al., 2006), regions (Stratoudakis et al., 1999; Eliasen et al., 2013), gears and years (Borges et al., 370 2005), among others.

372 Introducing a discard ban or landing obligation in combination with catch limits across 27 Member States, 11 fishing regions, 27 species, and approximately 84000 registered vessels 374 (EEC, 2011; Eurostat, 2012) may compromise the profitability of some discard-intensive 
fisheries at least in the short-term. A discard ban in isolation would increase costs and

376 decrease income if the catch includes significant proportions of unwanted organisms (Condie et al., unpubl. manuscript). But, if the benefits of non-compliance still outweigh the costs of

378 sanctions (Batsleer et al., 2013), there may be little incentive for those with increased costs to comply with the desired outcome of reduced discards. Thus, the introduction of a discard ban

380 will also require ancillary management measures such as catch quotas to stimulate more selective fishing practices (Condie et al., 2013). For the allocation of catch quotas it will be

382 important, as the European Commission noted, that these "need to reflect as much as possible the actual fishing patterns of vessels and their likely catch composition" (EEC, 2012c). This

384 study provides at a European scale a first portrayal of the fishing and discarding pattern for some of the considered species, fisheries and regions.

Our analysis of patterns in discard rates and ratios are based on measured numbers-at-length as opposed to length-weight-relationship-estimated weights. If weights were used, patterns may have differed depending on the proportion of small and light-weight individuals in

390 discarded fractions. For example, 100 discarded cod would have translated into a much greater weight than 100 discarded bogue or plaice, owing to differences in MLS (e.g. cod, <

$39238 \mathrm{~cm}$ in the Baltic Sea versus bogue, $<10 \mathrm{~cm}$ in the Mediterranean or plaice, $<27 \mathrm{~cm}$ ) and their body morphology (flat versus round shapes).

Our analysis is based on the assumption that all the sampling programmes considered here 396 have a similar degree of bias. Such bias may be associated with the selection of vessels on a voluntary basis, deployment of observers, and their sampling procedures. Deployment and observer bias (Benoît and Allard, 2009) are inherent to sampling programmes and difficult, if not impossible, to quantify. However, some of the sampling programmes used in this study were evaluated based on surrogate measures, such as comparing the relative biomass of 
marketable fish between observed and unobserved trips gleaned from logbooks (Tsagarakis et

402 al., 2008); the representativeness of sampled trips versus total effort in time and space (ICES, 2011); or selecting vessels for sampling from randomly-generated lists and where sampling

404 effort was allocated in proportion to the fisheries' annual fishing effort in the preceding year (Catchpole et al., 2011). Despite these shortcomings, on-board observer programmes remain

406 the most complete source of information on all components of the catch by fishing vessels.

408 The variability across samples resulted in wide confidence intervals for many discard rate estimates. If discard estimates are to be used in the future to set species-specific catch quotas

410 within reasonable confidence limits, observations from a much greater number of fishing trips will be needed to more precisely estimate discard amounts. Alternative, innovative sampling

412 techniques (e.g. self-sampling, Uhlmann et al., 2011; vessel monitoring by satellite systems, VMS, Hintzen et al., 2012; and closed-circuit TV, CCTV, Kindt-Larsen et al., 2011) may be

414 necessary to overcome the high costs of observers and resulting small sample sizes.

Otherwise, the number of species for which target precision levels can be achieved will 416 remain small.

418 Onboard observer programmes, in their complexity require, like any other scientific survey, uniform sampling standards, or at least their detailed description (Cotter and Pilling, 2007, 420 ICES, 2011) to allow for the inter-national integration of data. These programmes need to be continuously adapted because of perpetual changes in fishing activities. Despite some

422 institutional inertia, the national efforts and the international coordination have allowed significant progress to be made. This study contributes to further improvements. 
428 This study was carried out within the MariFish-funded BADMINTON project (Bycatch and Discards: management indicators, trends and location; http://83.212.243.10/badminton.html).

430 The funders had no role in study design, data collection and analysis, decision to publish, or preparation of the manuscript. Our thanks go out to all the skippers who were happy to take

432 observers onboard and likewise to all observers who diligently collected data.

References

Anonymous. 2009. Common tool for raising and estimating properties of statistical estimates 438 derived from the Data Collection Regulation. Studies and Pilot projects for carrying out the common fisheries policy. Project No SI2.467814, Brussels. 118 pp.

440 http://wwz.ifremer.fr/cost.

442 Batsleer J., Poos J.J., Marchal P., Vermard Y., Rijnsdorp A.D. 2013. Mixed fisheries management: Protecting the weakest link. Marine Ecology Progress Series, doi:

$444 \quad 10.3354 /$ meps 10203.

446 Benoît, H. P., and Allard, J. 2009. Can the data from at-sea observer surveys be used to make general inferences about catch composition and discards? Canadian Journal of Fisheries and 448 Aquatic Sciences, 66: 2025-2039.

450 Borges, L., Rogan, E., and Officer, R. 2005. Discarding by the demersal fishery in the waters around Ireland. Fisheries Research, 76: 1-13. 
Borges, L., Zuur, A. F., Rogan, E., and Officer, R. 2006. Modelling discard ogives from Irish 454 demersal fisheries. ICES Journal of Marine Science, 63: 1086-1095.

456 Catchpole, T. L., Enever, R., Maxwell, D. L., Armstrong, M. J., Reese, A., and Revill, A. S. 2011. Constructing indices to detect temporal trends in discarding. Fisheries Research, 107: $458 \quad 94-99$.

460 Catchpole, T. L., Rochet, M. J., Feekings, J., Madsen, N., Nikolic, N., Palialexis, A., Vassilopoulou, V., Valeiras, J., and Garcia, T. 2013. Using inferred drivers of discarding 462 behaviour to develop a fishery specific mitigation framework. Submitted manuscript (ICESJMS-2012-447) to ICES Journal of Marine Science 'Bycatch and Discards' symposium 464 issue.

466 Condie, H. M., Grant, A., and Catchpole, T. L. 2013. Incentivising selective fishing under a policy to ban discards; lessons from European and global fisheries. Marine Policy. 468

Condie, H. M, Grant, A., and Catchpole, T. L. unpublished manuscript. Does banning 470 discards in an otter trawler fishery create incentives for more selective fishing? Fisheries Research.

Cotter, A. J. R., and Pilling, G. M. 2007. Landings, logbooks and observer surveys:

474 improving the protocols for sampling commercial fisheries. Fish and Fisheries, 8: 123-152.

476 Crowder, L. B., and Murawski, S. A. 1998. Fisheries bycatch: Implications for management. Fisheries, 23: 8-17. 
Cumming, G., Fidler, F., and Vaux, D. L. 2007. Error bars in experimental biology. Journal of 480 Cell Biology, 177: 7-11.

482 Damalas, D., and Vassilopoulou, V. 2013. Slack regulation compliance in the Mediterranean fisheries: a paradigm from the Greek Aegean Sea demersal trawl fishery, modelling discard 484 ogives. Fisheries Management and Ecology, 20: 21-33.

486 Depestele, J., Vandemaele, S., Vanhee, W., Polet, H., Torreele, E., Leirs, H., and Vincx, M. 2011. Quantifying causes of discard variability: an indispensable assistance to discard 488 estimation and a paramount need for policy measures. ICES Journal of Marine Science, 68: $1719-1725$.

EEC. 2000. Council Regulation (EC) No 1543/2000 of 29 June 2000 establishing a

492 Community framework for the collection and management of the data needed to conduct the common fisheries policy. Brussels. Official Journal of the European Union, L 176: 1-16.

EEC. 2008. Council regulation (EC) No 199/2008 of 25 February 2008 concerning the 496 establishment of a community framework for the collection, management and use of data in the fisheries sector and support for scientific advice regarding the Common Fisheries Policy. 498 Official Journal of the European Union, L 60: 1-12.

500 EEC. 2009. Council Regulation (EC) No 409/2009 of 18 December 2009 adopting a multiannual Community programme for the collection, management and use of data in the 502 fisheries sector for the period 2011-2013. Official Journal of the European Union, L 41: 871. 
EEC. 2011. Proposal of 13 July 2011 for a regulation of the European Parliament and of the 506 Council on the Common Fisheries Policy. 2011/0195. Brussels. 87 pp.

508 EEC. 2012a. Proposal of 29 August 2012 for a regulation of the European parliament and of the council on certain technical and control measures in the Skagerrak and amending 510 Regulation (EC) No 850/98 and Regulation (EC) No 1342/2008. Brussels. 18 pp.

512 EEC. 2012b. Fisheries: commission acts to reduce discards in the west of Scotland. Press release of 23 February 2012. Directorate-General for Maritime Affairs and Fisheries, 514 Brussels.

516 EEC. 2012c. CFP reform - the discard ban. Information paper. http://ec.europa.eu/fisheries/reform/docs/discards_en.pdf.

Eliasen, S., Papadopoulou, N., Vassilopoulou, V., and Catchpole, T. (2013) Socio-economic 520 and institutional incentives influencing fishers behaviour in relation to fishing practices and discard. Submitted manuscript (ICES-JMS-2012-435) to ICES Journal of Marine Science

522 'Bycatch and Discards' symposium issue.

524 Eurostat. 2012. http://epp.eurostat.ec.europa.eu/portal/page/portal/eurostat/home/.

526 FAO. 1980. International standard statistical classification of fishing gear. ftp://ftp.fao.org/fi/document/cwp/handbook/annex/AnnexM1 fishinggear.pdf. 528

Feekings, J., Bartolino, V., Madsen, N., and Catchpole, T. 2012. Fishery discards: Factors 530 affecting their variability within a demersal trawl fishery. PLoS One, 7: e36409. 
532 Helmond, A.T.M., and Uhlmann, S.S. (eds) 2011. Report on an overview of existing discard data by métier, area, and member state. MariFish, London. 300 pp.

534 http://83.212.243.10/badminton.html.

536 Hintzen, N. T., Bastardie, F., Beare, D., Piet, G. J., Ulrich, C., Deporte, N., Egekvist, J., et al. 2012. VMStools: Open-source software for the processing, analysis and visualisation of 538 fisheries logbook and VMS data. Fisheries Research, 115-116: 31-43.

540 Hinz, H., Murray, L. G., Lambert, G. I., Hiddink, J. G., and Kaiser, M. J. (2013).

Confidentiality over fishing effort data threatens science and management progress. Fish and

542 Fisheries. Article first published online : 22 May 2012, doi: 10.1111/j.1467-

2979.2012.00475.x

544

ICES. 2007. Report of the Working Group on Discard Raising Procedures, 6-9 February 546 2007, San Sebastian, Spain. ICES CM 2007 ACFM:06. Copenhagen.

548 ICES. 2009. Definition of a standard data-exchange format for sampling, landings, and effort data from commercial fisheries. ICES Cooperative Research Report No. 296, Copenhagen. 44 550 pp.

552 ICES. 2010. Report of the ICES Workshop on ecosystem indicators of discarding (WKEID), 28 September - 1 October 2010, Copenhagen. 60 pp.

ICES. 2011. Report of the Study Group on Practical Implementation of Discard Sampling plans (SGPIDS). ICES Advisory Science Committee. ICES CM 2011/ACOM:50, 
Copenhagen. $110 \mathrm{pp}$.

558

ICES. 2012. Report of the Planning Group on Commercial Catches, Discards And Biological 560 Sampling (PGCCDBS). 30th January - 3rd February, 2012, Rome. 163 pp.

562 Kennelly, S. J., and Broadhurst, M. K. 2002. By-catch begone: changes in the philosophy of fishing technology. Fish and Fisheries, 3: 340-355.

Kindt-Larsen, L., Kirkegaard, E., and Dalskov, J. 2011. Fully documented fishery: a tool to 566 support a catch quota management system. ICES Journal of Marine Science, 68: 1606-1610.

568 Limpert, E., Stahel, W.A., and Abbt, M. 2001. Log-normal distributions across the sciences keys and clues. BioScience 51, 341-352.

Madsen, N., Feekings, J., and Lewy, P. 2013. Discarding of plaice (Pleuronectes platessa) in 572 the Danish North Sea trawl fishery. Journal of Sea Research, 75: 129-134.

574 Madsen, N., and Valentinsson, D. 2010. Use of selective devices in trawls to support recovery of the Kattegat cod stock: a review of experiments and experience. ICES Journal of Marine 576 Science, 67: 2042-2050.

578 Nelson, G. A. 2011. Package 'fishmethods'. March 27, 2012 Massachusetts Division of Marine Fisheries. http://cran.r-project.org, accessed on 12/06/2012.

Poos, J. J., Aarts, G., Vandemaele, S., Willems, W., Bolle, L. J., and van Helmond, A. T. M. 582 2013. Estimating spatial and temporal variability of juvenile North Sea plaice from 
opportunistic data. Journal of Sea Research, 75: 118-128.

Punt, A. E., Smith, D. C., Tuck, G. N., and Methot, R. D. 2006. Including discard data in

586 fisheries stock assessments: two case studies from south-eastern Australia. Fisheries Research, 79: 239-250.

R Development Core Team. 2005. R: a Language and Environment for Statistical Computing.

590 R Foundation for Statistical Computing, Vienna, Austria. http://cran.r-project.org.

592 Rochet, M.-J., and Trenkel, V. 2005. Factors for the variability of discards: assumptions and field evidence. Canadian Journal of Fisheries and Aquatic Sciences, 62: 224-235.

STECF. 2006. Commission staff working paper report of the scientific, technical, and economic committee for fisheries discards from community vessels: opinion expressed during a plenary meeting held in Ispra from 6-10 November 2006. 56 pp.

STECF. 2008. Commission staff working paper report of the scientific, technical, and 600 economic committee for fisheries discards from community vessels: opinion expressed during a plenary meeting of 14-18 April 2008 in Hamburg. 206 pp.

Stergiou, K. I., Christou, E. D., Georgopoulos, D., Zenetos, A., and Souvermesoglou, C. 604 1997. Hellenic Seas: physics, chemistry, biology and fisheries. Oceanography and Marine Biology: An Annual Review, 35: 415-538.

Stratoudakis, Y., Fryer, R. J., Cook, R. M., and Pierce, G. J. 1999. Fish discarded from 608 Scottish demersal vessels: Estimators of total discards and annual estimates for targeted 
gadoids. ICES Journal of Marine Science, 56: 592-605.

610

Tsagarakis, K., Machias, A., Giannoulaki, M., Somarakis, S., and Karakassis, I. 2008.

612 Seasonal and temporal trends in metrics of fish community for otter-trawl discards in a Mediterranean ecosystem. ICES Journal of Marine Science, 65: 539-550.

Uhlmann, S. S., Bierman, S. M., and Helmond, A. T. M. van 2011. A method of detecting

616 patterns in mean lengths of samples of discarded fish, applied to the self-sampling programme of the Dutch bottom-trawl fishery. ICES Journal of Marine Science, 68: 17126181718.

620 Viana, M., Graham, N., Wilson, J. G., and Jackson, A. L. 2011. Fishery discards in the Irish Sea exhibit temporal oscillations and trends reflecting underlying processes at an annual 622 scale. ICES Journal of Marine Science, 68: 221-227.

624 Wigley, S. E., Blaylock, J., Rago, P. J., Murray, K. T., Nies, T. A., Seagraves, R. J., Potts, D., Drew, K. 2012. Standardized Bycatch Reporting Methodology 3-year Review Report - 2011

626 Part 2. US Department of Commerce, Northeast Fisheries Science Centre Reference Document 12-27; 226 pp. Available from: National Marine Fisheries Service, 166 Water

628 Street, Woods Hole, MA 02543-1026, or online at http://www.nefsc.noaa.gov/nefsc/publications/ 
632 Table 1. Sampling allocation schemes, species identification and measurement procedures, and raising units of national discard sampling programmes part of the European Data Collection

634 Framework (DCF).

Programme

Allocation $^{\mathrm{a}}$

Identification

Measurement $^{\mathrm{c}}$

Raising unit $^{\mathrm{d}}$

Denmark
All DCF-fisheries
Random
Partial
Numbers/weights
Fishing operation

Spain

Otter trawl (Med. Sea) Opportunistic Partial

Otter trawl (Atlantic) Random Partial
Numbers/weights Fishing operation

Numbers/weights Fishing operation

642 France
All DCF-fisheries
Opportunistic All
Numbers/weights
Fishing operation

644 England
All DCF-fisheries
Random
All
Numbers
Fishing operation

646 Greece

Otter trawl

Random

All

Numbers/weights

Fishing operation

648 Netherlands

Beam trawl Opportunistic All

Numbers

Fishing time

${ }^{\mathrm{a}}$ Allocation of sampling effort. For example, how the units of the sampling frame (e.g. vessels, trips) were chosen: by a (stratified) random, opportunistic/cooperative design (ICES, 2011).

${ }^{\mathrm{b}}$ Identification of either all or selected (partial) species within a catch sample.

${ }^{\mathrm{c}}$ Measurement includes numbers and/or weights of discarded or landed species.

$654{ }^{\mathrm{d}}$ Sampling unit includes the estimator used to raise species numbers/weights from haul to trip level. 
Table 2. List of discard-intensive, towed-gear fisheries for which data were provided by country; together with an indication of the range of fishing and sampling effort within a given period:

number of registered vessels, annual total and \% observed fishing effort (days at sea, D.A.S.).

658

\begin{tabular}{lcccc}
\hline Fishery Country & Period & No. vessels & Total & $\%$ observed \\
& & D.A.S. & D.A.S.
\end{tabular}

Otter trawl for crustaceans

$\begin{array}{lcccc}\text { Denmark } & 2003-08 & 221-350 & 15719-28152 & 0.29-0.55 \\ \text { France } & 2003-08 & 390-504 & 104310-161280 & 0.11-0.26 \\ \text { England } & 2002-08 & \text { NA } & 4179-5161 & 0.19-1.29\end{array}$

Otter trawl for fish

$\begin{array}{lcccc}\text { Denmark } & 2003-08 & 476-809 & 27706-57687 & 0.22-0.71 \\ \text { Spain }^{\mathrm{a}} & 2003-07 & 167-210 & 109683-294673 & 0.05-0.12 \\ \text { Spain }^{\mathrm{b}} & 2003-08 & 182-188 & 23512-34664 & 0.12-0.19 \\ \text { Greece } & 2003-06 & 5-12 & 378-2545 & 4.37-34.56 \\ \text { Greece }^{\mathrm{c}} & 2003-08 & 326-336 & 53624-59552 & 0.06-0.22 \\ \text { France } & 2003-08 & 1530-1832 & 550800-616600 & 0.05-0.17 \\ \text { England } & 2002-08 & \text { NA } & 31612-50578 & 0.17-0.51\end{array}$

Beam trawl for fish

$\begin{array}{lcccc}\text { Denmark } & 1997-2008 & 2-17 & 313-2111 & 0.00-5.16 \\ \text { France } & 2003-05 & 42-79 & 15120-27876 & 0.09-0.15 \\ \text { Netherlands } & 2003-08 & 99-139 & 14210-21027 & 0.17-0.30 \\ \text { England } & 2002-08 & \text { NA } & 30929-49384 & 0.15-0.47\end{array}$

$660{ }^{a}$ Fishery active in North-East Atlantic ICES Divisions: VIIb; VIIc; VIIj; VIIk; VIIg; VIIh; VIIc; and IXa.

$662{ }^{\mathrm{b}}$ Fishery active in the Western Mediterranean Sea: GSA3701.

${ }^{\mathrm{c}}$ Different otter trawl fleets in the Greek part of the Mediterranean Sea were considered as a single 664 fishery. 
Table 3. Coefficients of variation (\%) of discard rates, where applicable, for selected species calculated across fisheries for a given region (inter-

666 fishery) and across regions for a given fishery (inter-region).

668

\begin{tabular}{cc}
\hline & Atlantic cod \\
\hline Inter-fishery & \\
Baltic Sea & 14 \\
Celtic Sea &
\end{tabular}

Irish Sea

$674 \quad$ Mediterranean

North Sea

676

Skagerrak

Inter-region

678

Otter trawls

(crustaceans)

680

Otter trawls

(fish)

682

Beam trawls

(fish)

$62-77$
15

$15 \quad 48$

53
European

European

Red mullet

Deep-water

rose shrimp

plaice

83

14

70

80

109

63

104

114

126

120 
Table 4. Coefficients of variation (\%) of discard ratios, where applicable, for selected species, calculated across fisheries for a given region (inter686 fishery) and across regions for a given fishery (inter-region).

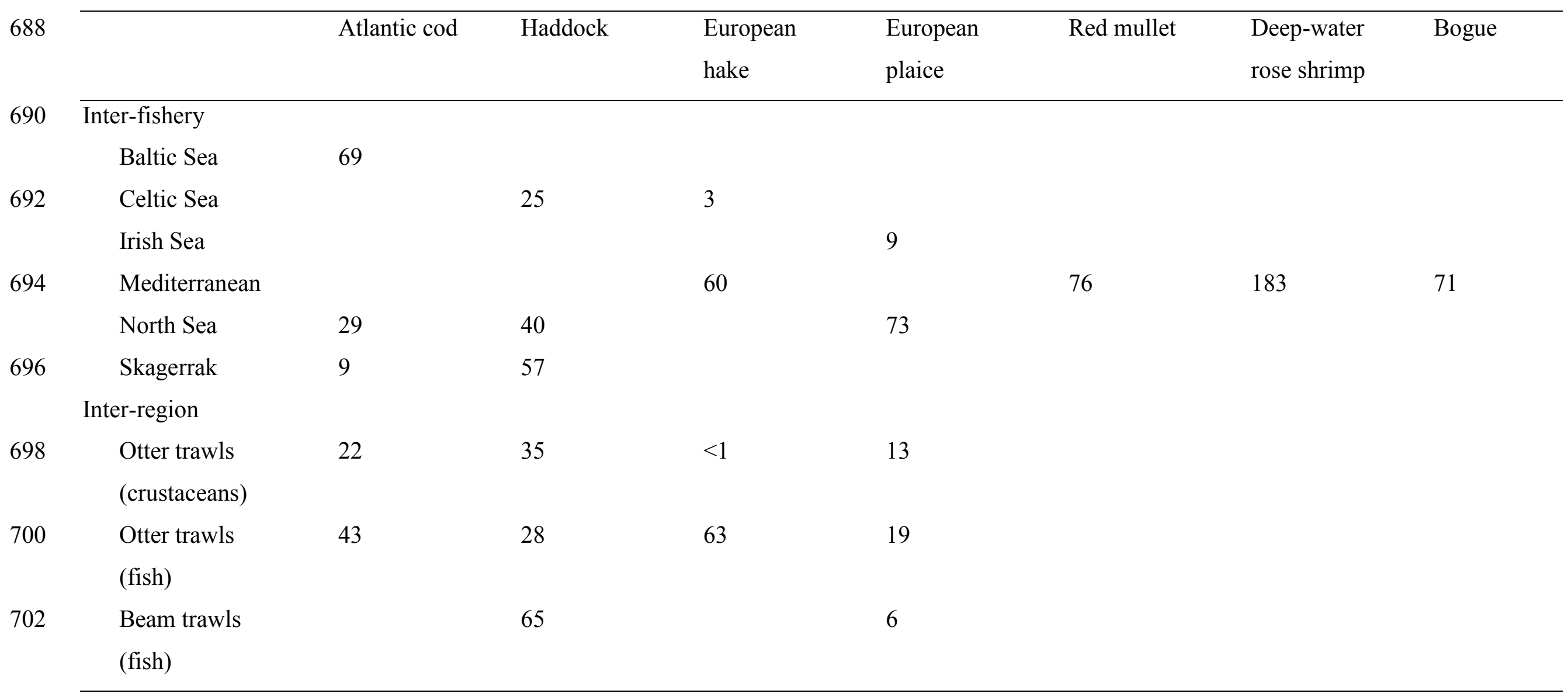


Figures

706

Figure 1. Discard and landings rates (with inferential error bars) of commercially-valuable

708 species across fisheries for a given region (inter-fishery, top row) and across regions for a given fishery (inter-region, bottom row of plots): (a) Atlantic cod; (b) haddock; (c) European

710 hake; and (d) European plaice, when combined across countries and ICES Divisions; and (e) red mullet; (f) deep-water rose shrimp; and (g) bogue when combined across countries fishing

712 in the Mediterranean Sea. To improve visibility of bar plots, the y-axis scaling was broken where large differences between landings and discard rates existed. The number above each

714 bar represent the number of observed trips (if $\geq 4$ ). 
(a) Atlantic cod
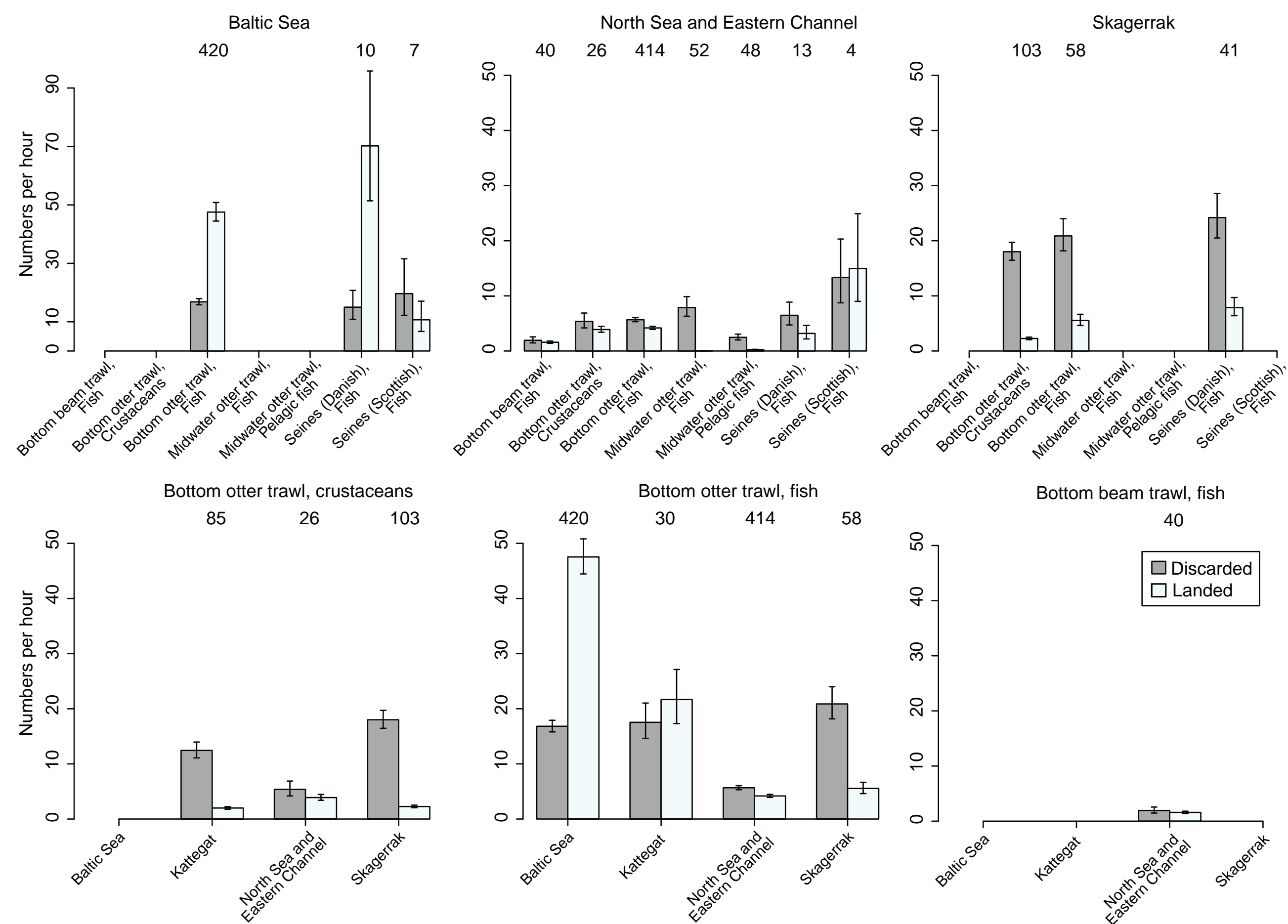

Bottom beam trawl, fish

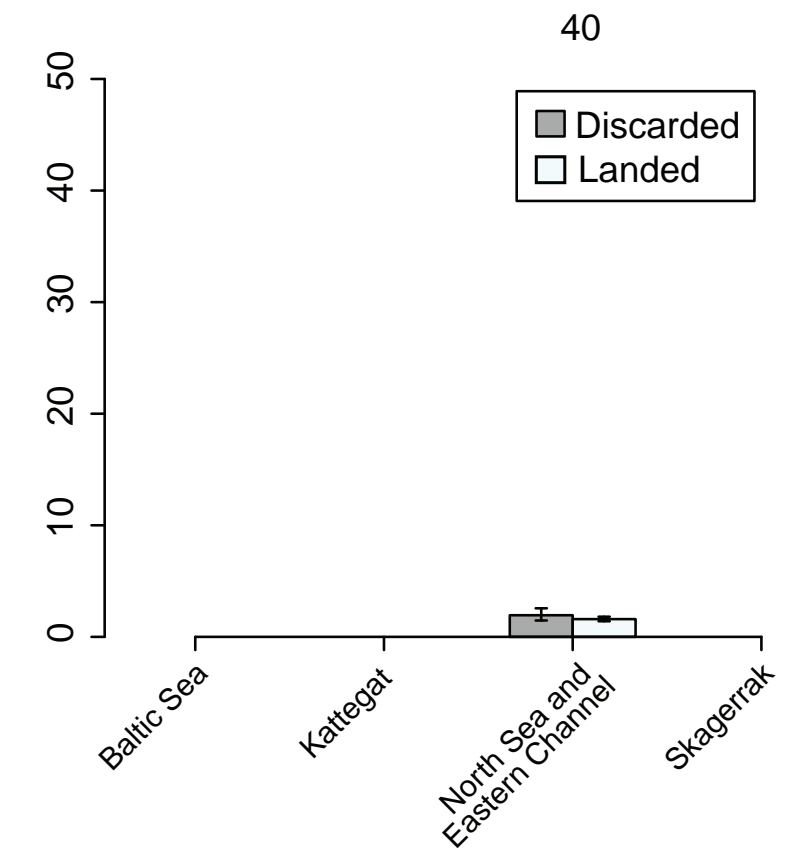


(b) Haddock
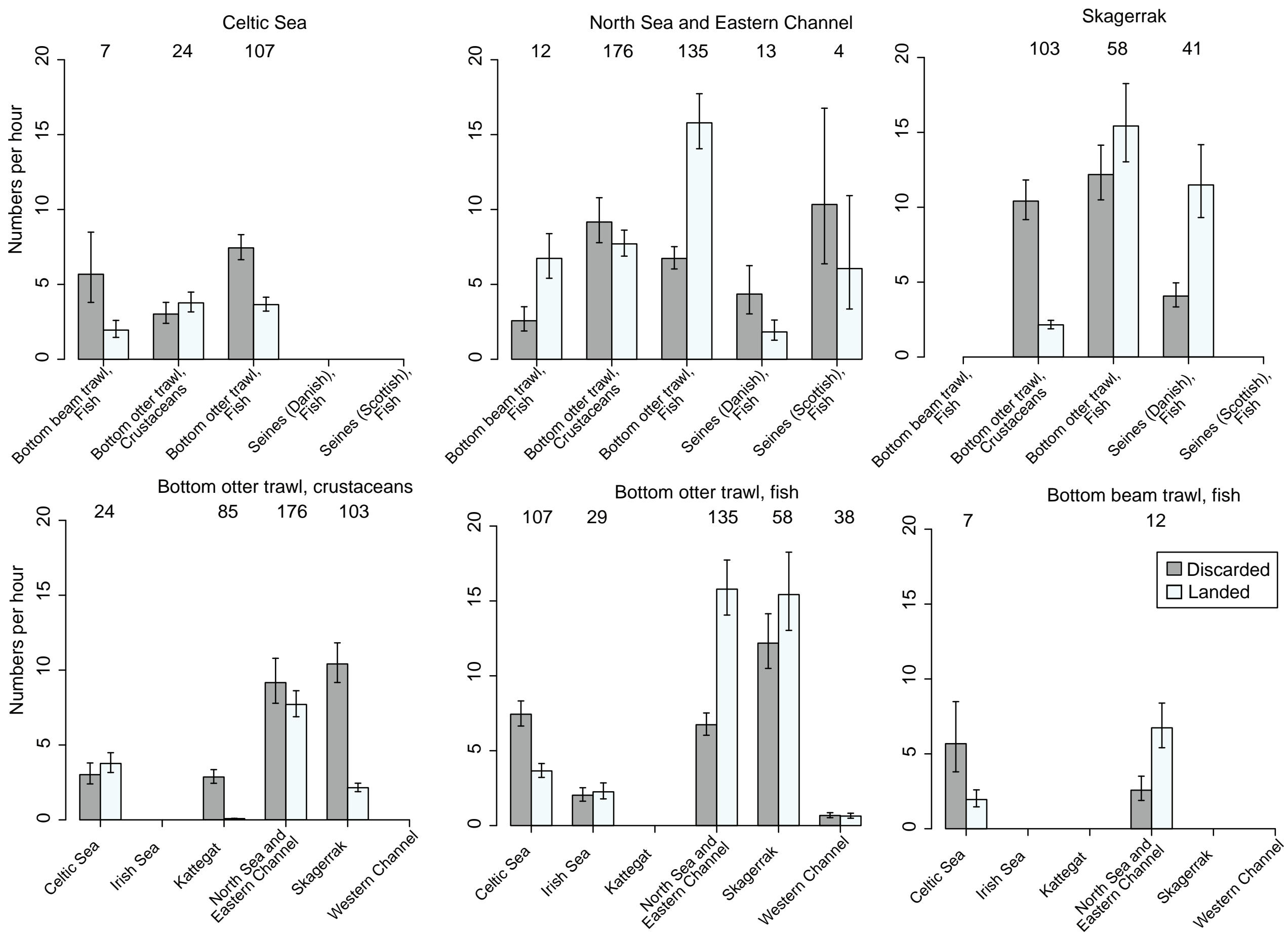
(c) European hake

Celtic Sea

24

22
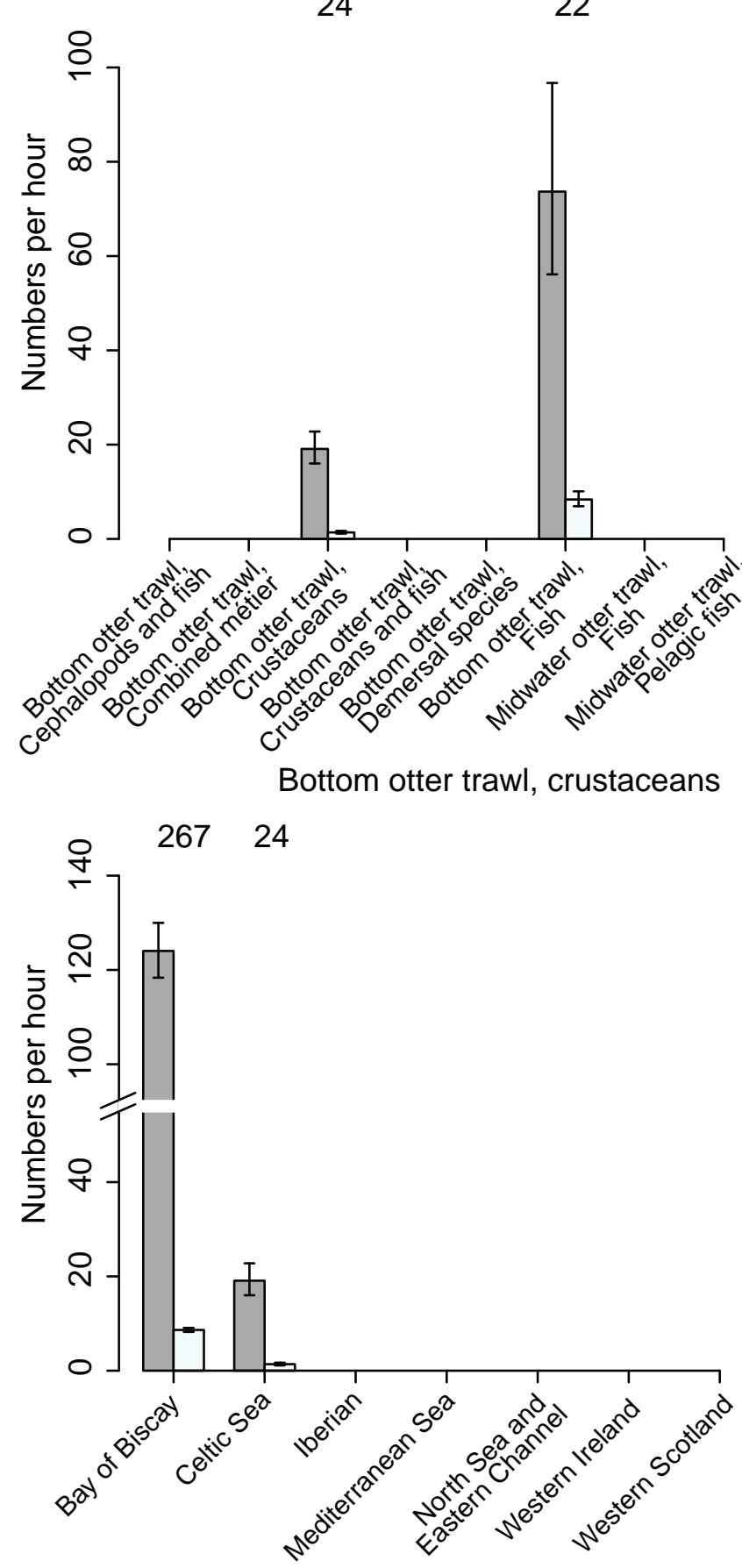

Mediterranean Sea

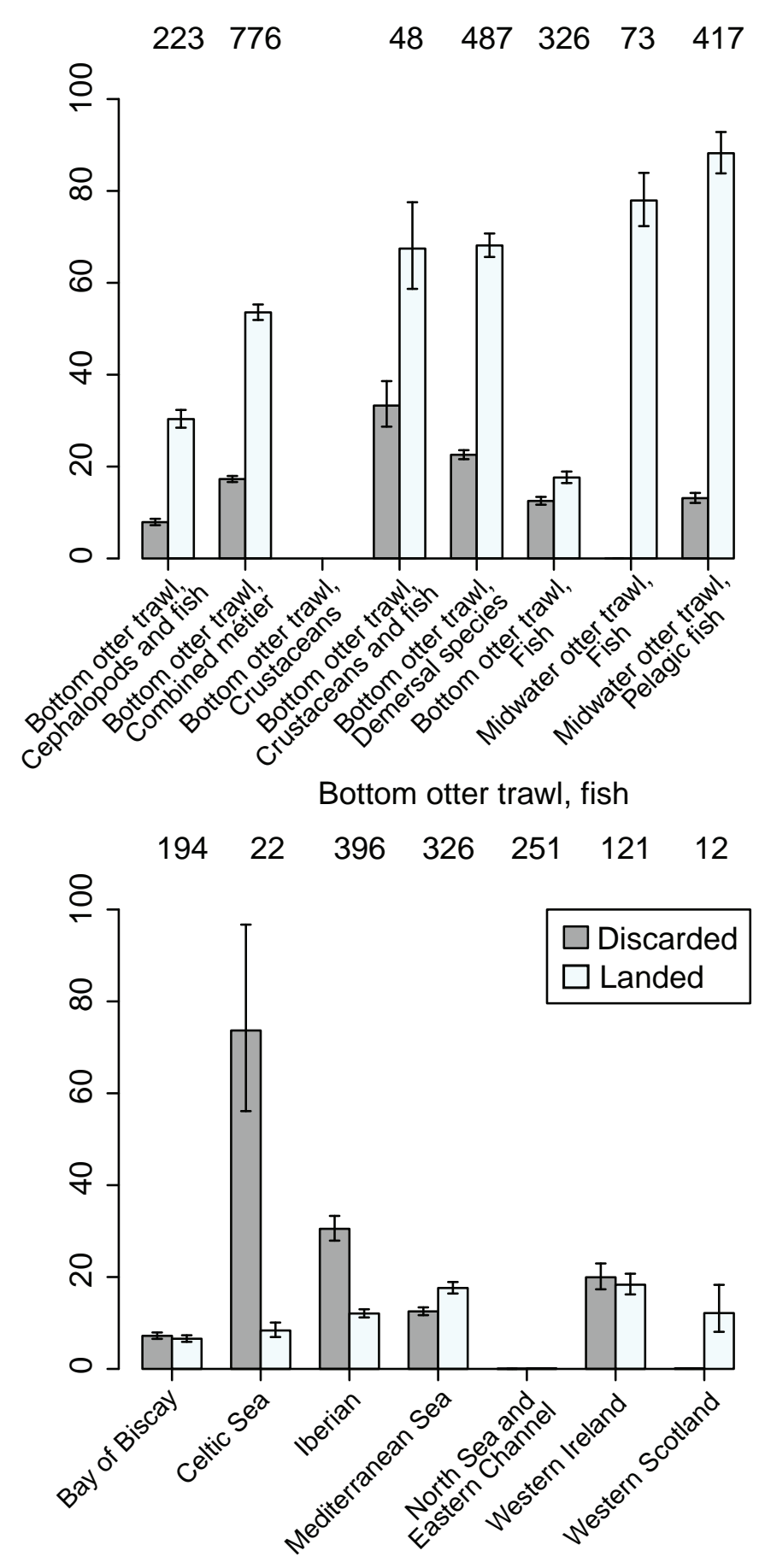


(d) European plaice

Celtic Sea
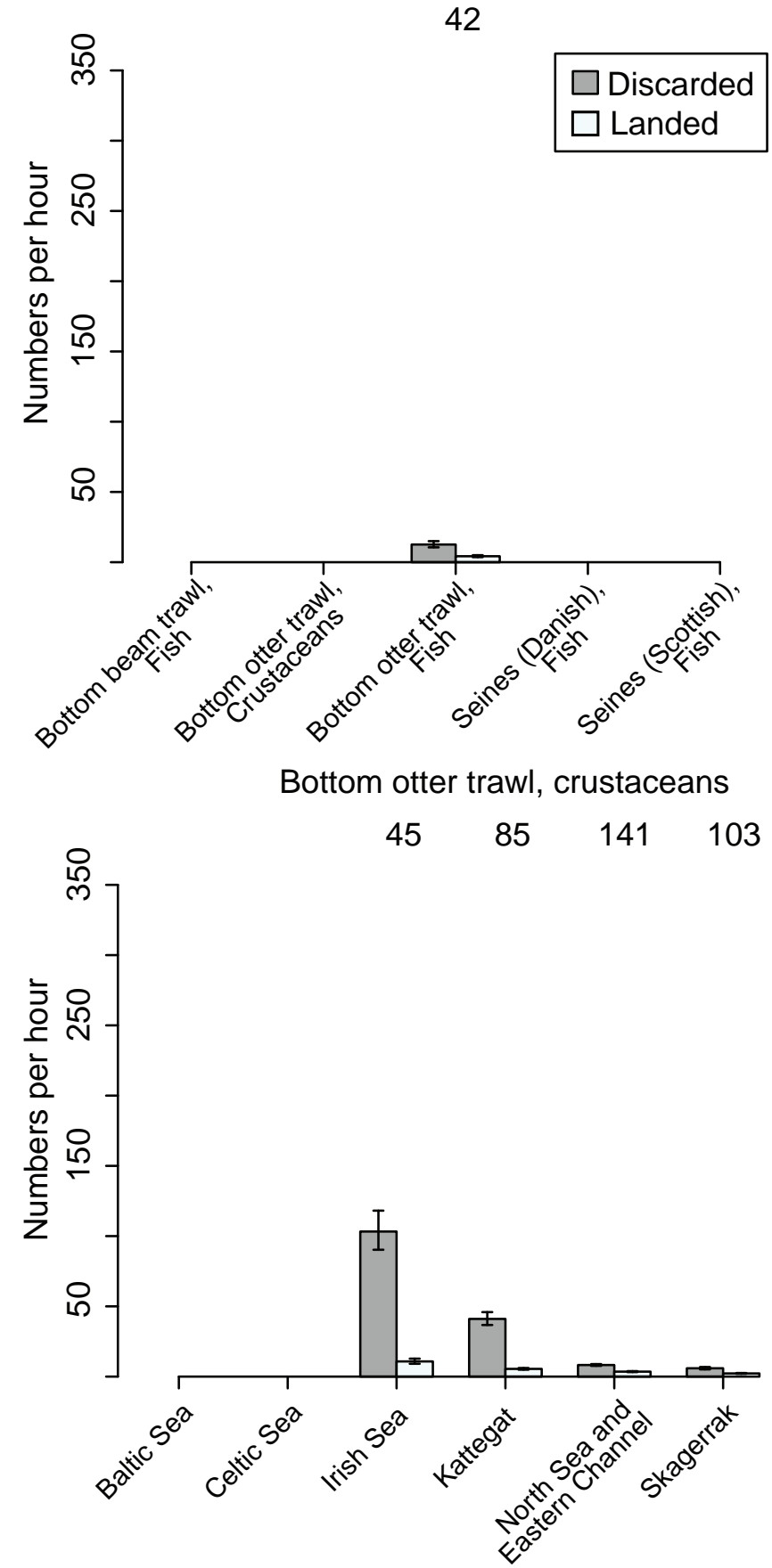

Irish Sea
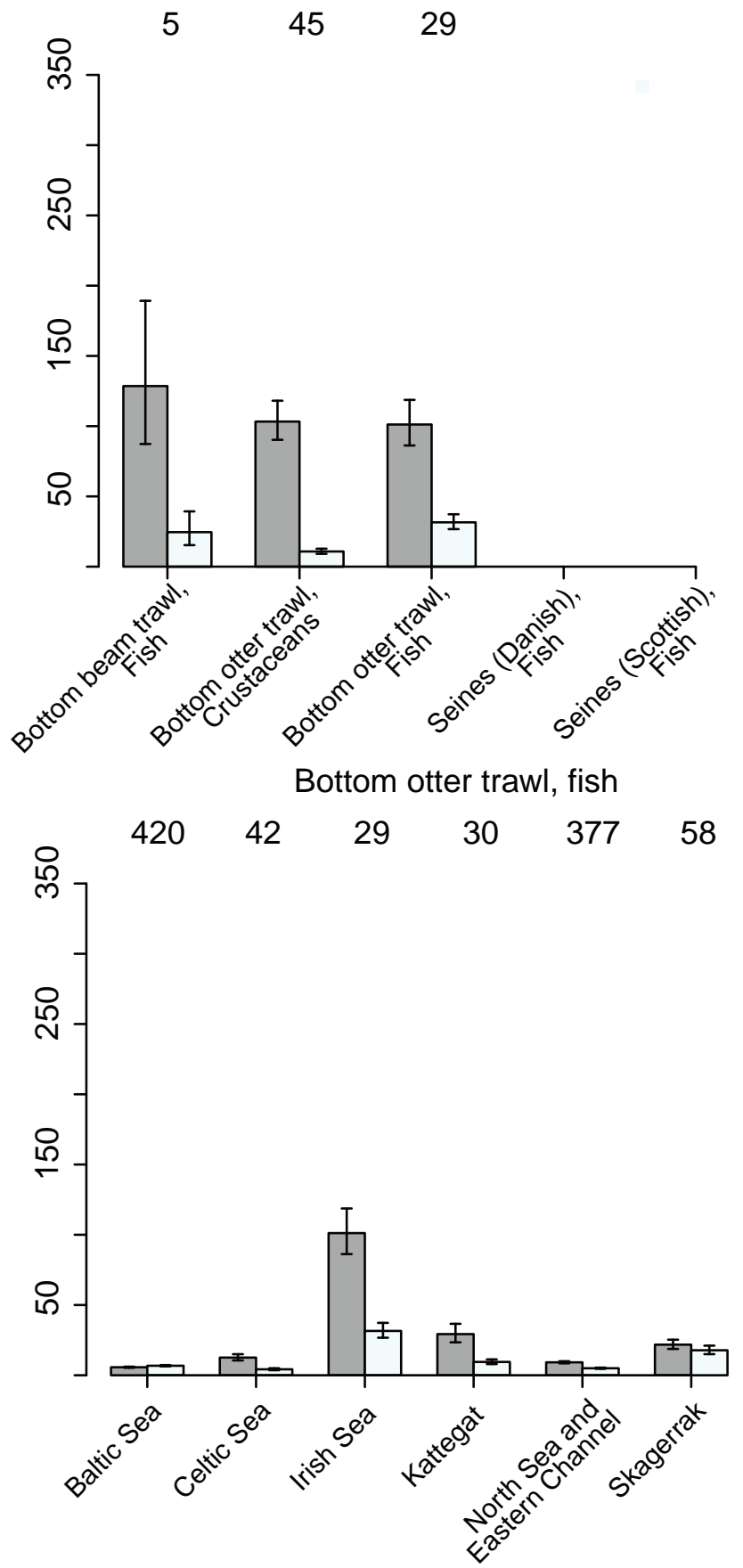

North Sea and Eastern Channel

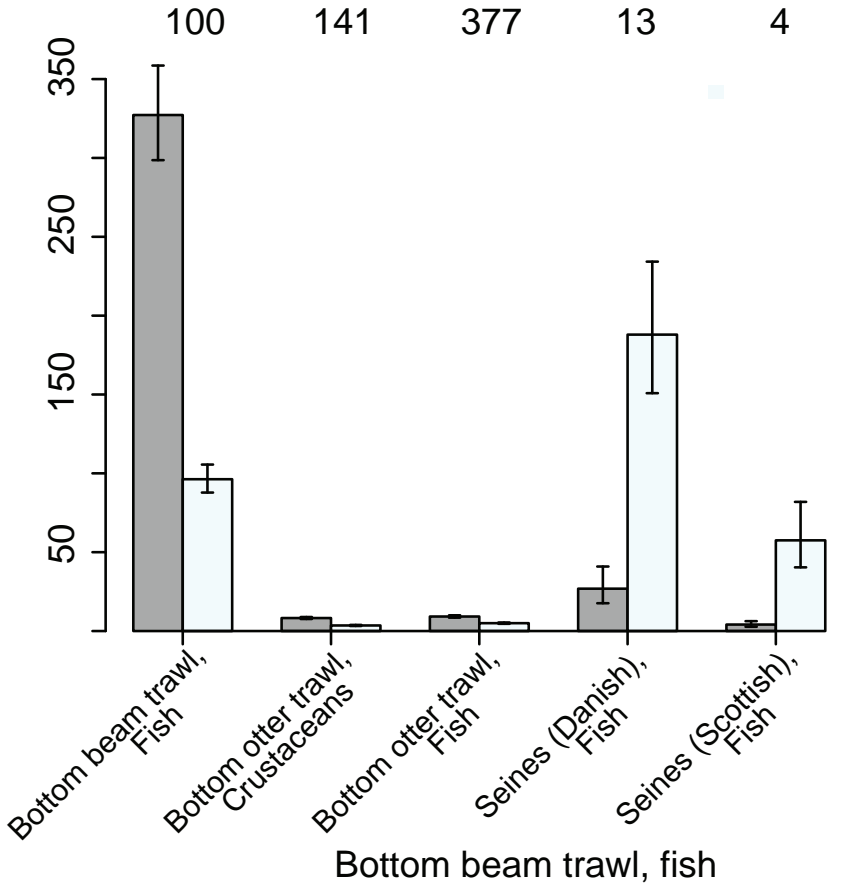

5

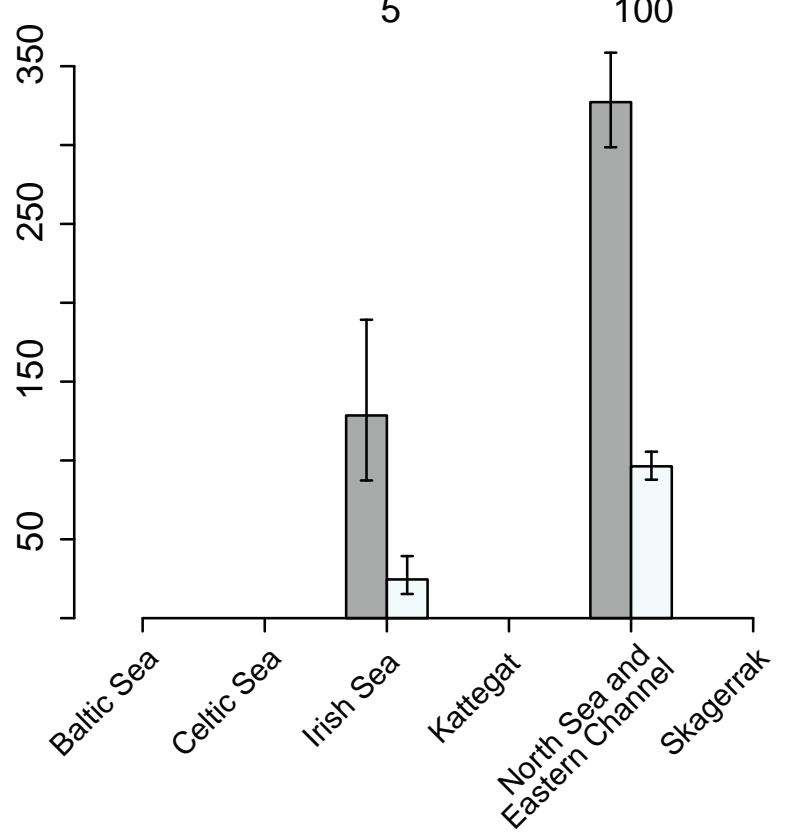


(e) Red mullet

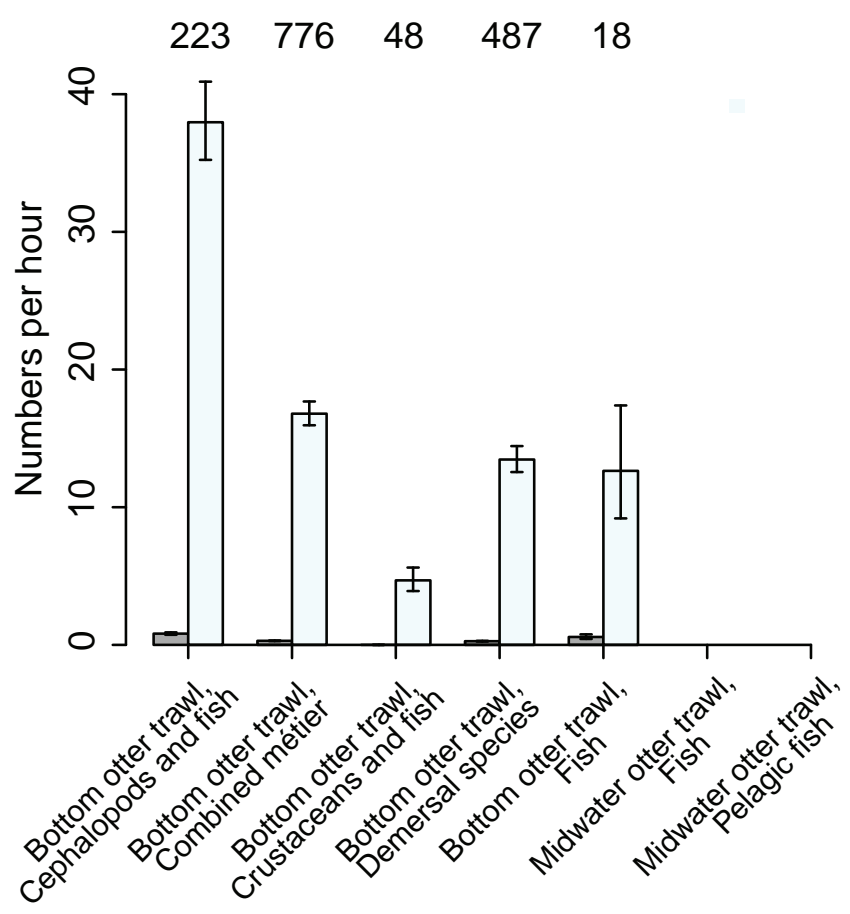

(f) Deep-water rose shrimp

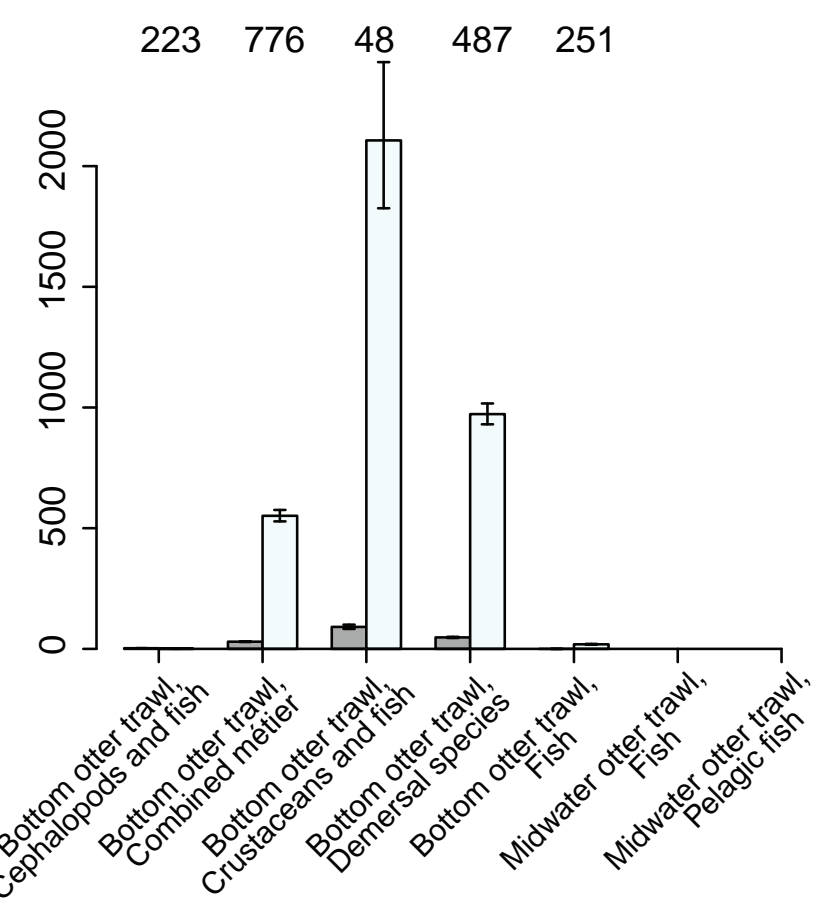

(g) Bogue

$\square$ Discarded $\square$ Landed

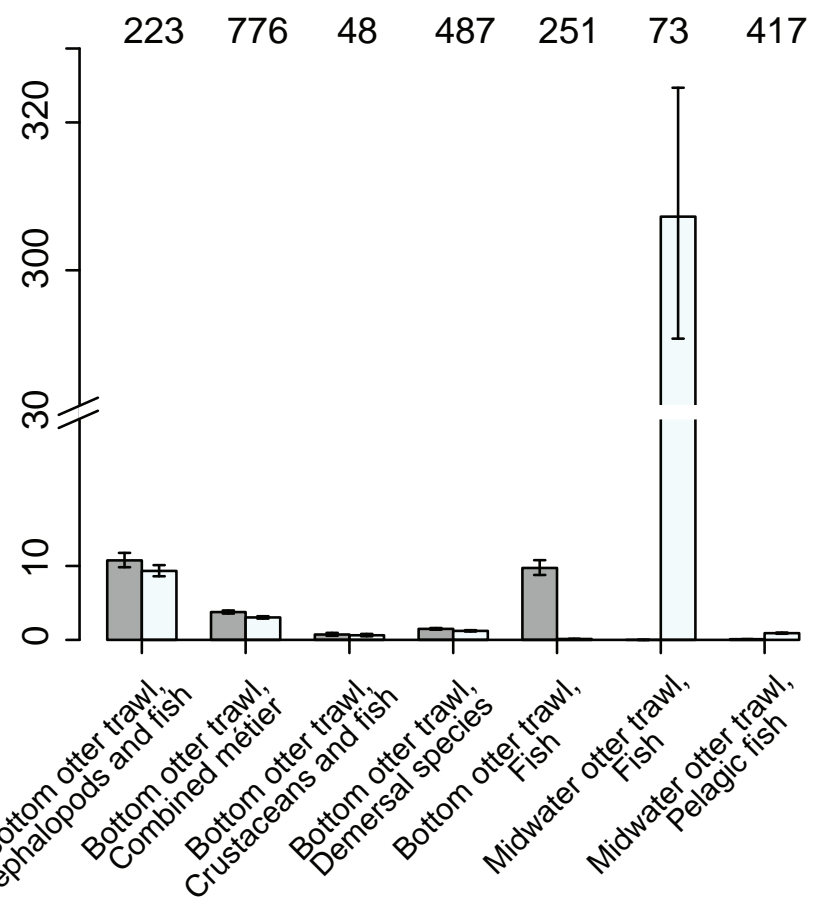

